\title{
molecules
}

ISSN 1420-3049

(C) 2008 by MDPI

www.mdpi.org/molecules

Full Paper

\section{Spirowallichiione: A Rearranged Multiflorane from Euphorbia wallichii Hook F. (Euphorbiaceae)}

\author{
Muhammad Shaiq Ali ${ }^{1, *}$, Shakeel Ahmed ${ }^{1}$ and Muhammad Saleem ${ }^{1,2}$ \\ ${ }^{1}$ H.E.J. Research Institute of Chemistry, International Center for Chemical and Biological Sciences \\ (ICCBS), University of Karachi, Karachi-75270, Pakistan \\ 2 Department of Chemistry, Baghdad-ul-Jadeed Campus, The Islamia University Bahawalpur, Pakistan \\ * Author to whom correspondence should be addressed; E-mail: shaiq303@hotmail.com; Tel: (+ 92) \\ 21-4824930; Fax: (+ 92) 21-4819018
}

Received: 11 January 2008; in revised form: 4 February 2008 / Accepted: 4 February 2008 / Published: 18 February 2008

\begin{abstract}
Euphorbia wallichii of the family Euphorbiaceae yielded a new rearranged pentacyclic triterpene of the multiflorane class which we have named spirowallichiione. The structure of this natural spirocompound was elucidated with the aid of modern spectroscopic techniques, including 2D-NMR.
\end{abstract}

Keywords: Euphorbia wallichii; Euphorbiaceae; rearranged multiflorane; spirowallichiione; characterization

\section{Introduction}

The Euphorbiaceae constitute one of the largest families of higher plants, comprising about 300 genera and 7,500 species. The genus Euphorbia is one of the six largest genera of flowering plants, having approximately 2,160 species. The Euphorbias are supposedly named after Euphorbus, a Greek physician to Juba II, the Romanized king of Numidia, who is said to have used the plant's milky latex as an ingredient in his medicinal preparations. Some of the plants belonging to the genus Euphorbia have been used in folk medicine for hundreds of years. They have been used for the treatment of cancers, tumors, migraine, skin diseases, gonorrhea, intestinal parasites and warts [1-2]. E. 
antisyphi1itica is a popular herbal remedy in India, where it is used for the treatment of liver ailments [3]. E. prostrate is also applied in Indian folk medicines as an anti-inflammatory and blood purifier [4]. The extract of $E$. fischeriana is used in the manufacture of an ointment for psoriasis (a chronic skin disease in which red scaly pustules and patches appear) [5]. Latex of E. lateriflora is used as a treatment for ringworm and in dilute aqueous solution, as a purgative [6]. It is also considered as a remedy for enlargement of the liver and spleen [7]. Roots of E. wallichii have been traditionally used in Tibetan folk medicines for the treatment of edema and skin disease such as furuncle, exanthema and cutaneous anthrax [8].

Members of Euphorbia are rich in phenolics [9], aromatic esters [9], steroids [10], diterpenoids [11-16], tetracyclic triterpenoids [10], pentacyclic triterpenoids [9,11], essential oils [17] and several bioactive constituents [18-19]. A chemical literature survey of E. wallichii, an endemic plant of Pakistan, revealed mentions of the presence of abietane [20] and rearranged diterpenoids [21]. This prompted us to investigate Euphorbia wallichii for its chemical constituents. We report herein the identification of a new rearranged triterpenoid of the multiflorane class isolated from this source.

\section{Results and Discussion}

Compound 1, named spirowallichiione, was obtained as a white powder (mp: $210-212^{\circ} \mathrm{C}$ ) by elution of a silica gel column loaded with methanol soluble part of E. wallichii with $10 \%$ ethyl acetate in hexane.

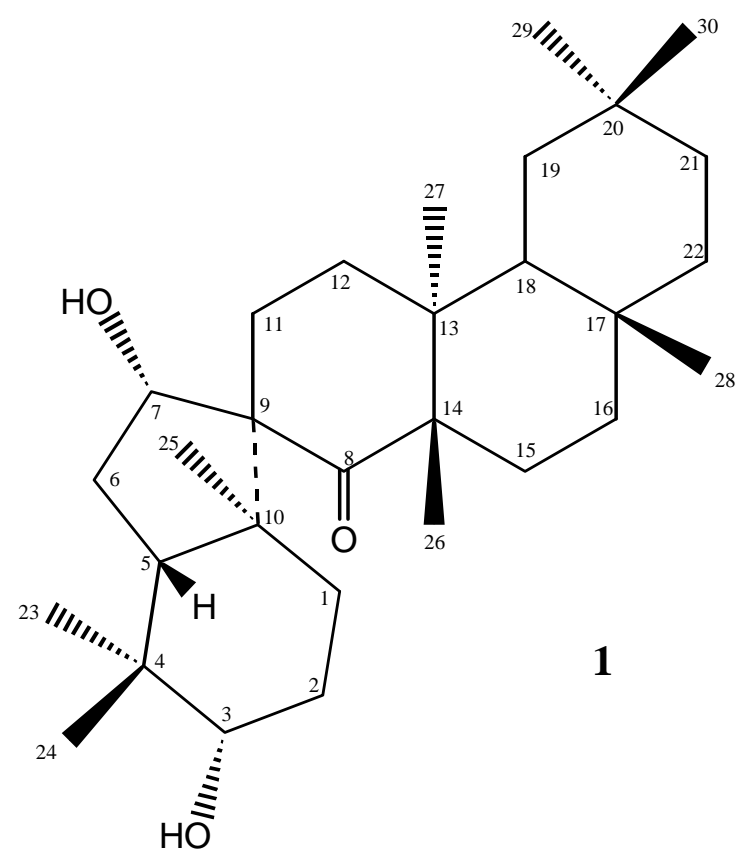

Its infrared spectrum displayed two prominent absorptions at 3416 and $1641 \mathrm{~cm}^{-1}$, attributed to the presence of hydroxyl and ketone functionalities, respectively. The molecular mass of $\mathbf{1}$ was determined from the peak at $\mathrm{m} / \mathrm{z} 458$ obtained by Field Desorption Mass Spectrometry and the formula of corresponding peak was confimed as $\mathrm{C}_{30} \mathrm{H}_{50} \mathrm{O}_{3}$ via a High Resolution Electron Impact Mass Spectrum. The proton NMR spectrum of 1 exhibited eight methyl singlets between $\delta$ 0.86-1.22, suggesting its triterpenic nature. In addition to these methyl singlets, the spectrum showed two significant doublet of 
doublets signals at $\delta 3.47(J=9.8,6.1 \mathrm{~Hz})$ and $4.20(J=7.1,7.1 \mathrm{~Hz})$, attributable to the $\mathrm{H}-3$ and $\mathrm{H}-7$ carbinylic protons, respectively. The remaining signals are described in the Experimental section.

The ${ }^{13} \mathrm{C}$-NMR (broad-band) spectrum of $\mathbf{1}$ displayed altogether 29 carbon signals, while the formula obtained from HR-EIMS indicated a $\mathrm{C}_{30}$ molecule. DEPT experiments resolved these signals into eight methyls, ten methylenes, four methines and the remaining eight signals as quaternary carbons. A signal at $\delta 21.8$ in the broad-band spectrum was resolved into two signals as a methyl and a methylene in the DEPT experiments. Thus, the triterpenic nature was reconfirmed. The carbinylic carbons resonated at $\delta 79.3(\mathrm{C}-3)$ and $77.9(\mathrm{C}-7)$. A downfield signal at $\delta 220.1$ was due to the ketone function in the molecule. The detailed ${ }^{13} \mathrm{C}-\mathrm{NMR}$ data are given in the Experimental section.

When the NMR data of $\mathbf{1}$ were compared with that of the various classes of pentacyclic triterpenoids, it was observed that compound $\mathbf{1}$ is very close to the multiflorane class 1a. During the comparison of NMR spectral data, it was noticed that some of the NMR signals due to rings A, B and $\mathrm{C}$ in a reported rearranged natural triterpenoid of the fernane class obtained from E. supina named spirosupinanonediol are comparable with the data of $\mathbf{1}$ [22]. Thus, it was concluded that $\mathbf{1}$ is a rearranged-multiflorane. This rearrangement can be explained as shown in Figure 1, where bond breaking between C-7 and C-8 and bond rotation about C-9 and C-10 can account for the structure of spirocompound $\mathbf{1}$.

Figure 1. Fernane/spirosupinanonediol relationship and possible multiflorane (1a) to spirowallichiione (1) rearrangement.

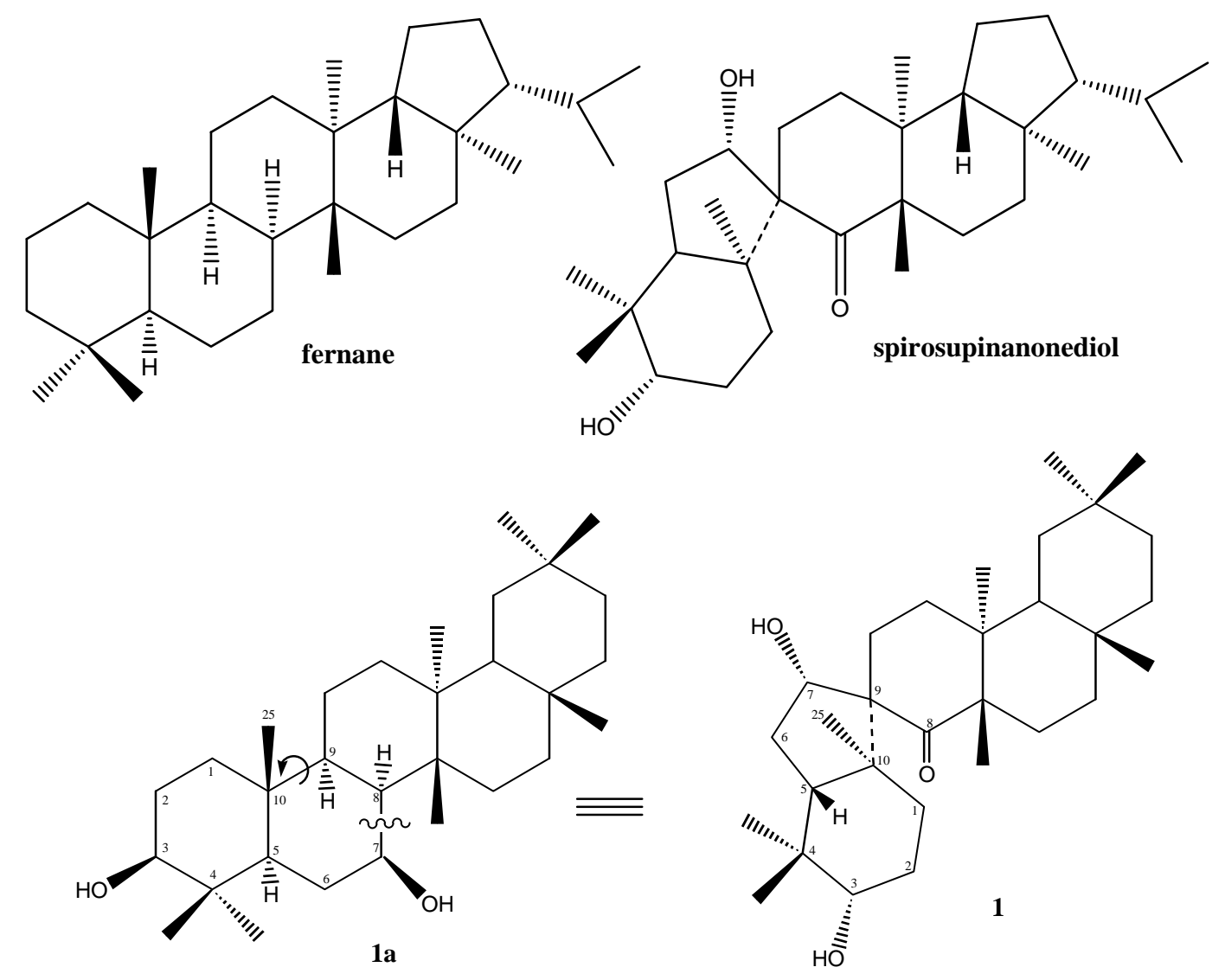


The structure of the rearranged part (rings-A to $\mathrm{C}$ ) of the molecule in $\mathbf{1}$ was deduced from the HMBC connectivities (see Figure 2) and cross-checked via a COSY experiment (see Figure 3). The stereochemistry of the hydroxyl functions in the molecule was determined as $\alpha$ at both C-7 and C-3. In the case of the C-7 hydroxyl, this fact was established by NOESY experiment (Figure 3), while at C-3 the magnitude of coupling constants was the determining factor for this conclusion. In nature, most of pentacyclic triterpenoids having a hydroxyl function at C-3 are equatorial with a $\beta$ orientation. In compound 1, the magnitude of coupling constant $(J=9.8,6.1 \mathrm{~Hz})$ due to the $\mathrm{H}-3$ carbinylic proton suggested an equatorial orientation of the hydroxyl but facing towards the $\alpha$-face due to the fact that ring-B has twisted after bond rotation along C-9 and C-10 (fig. 1).

Figure 2. Important HMBC connectivities in $\mathbf{1 .}$

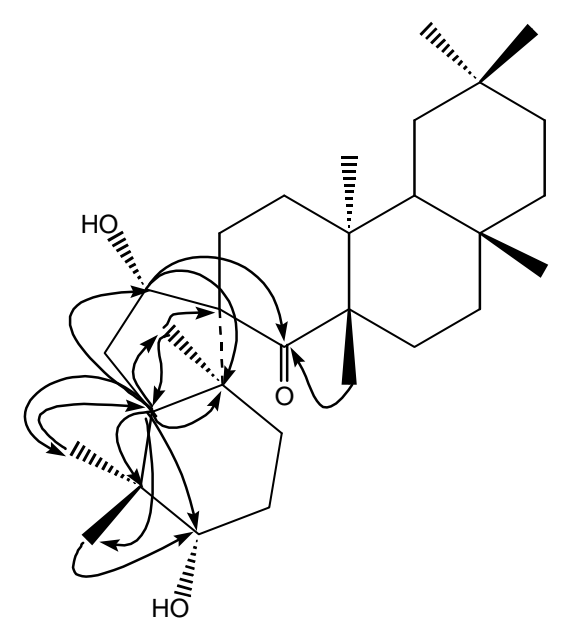

Figure 3. Important COSY (-) and NOESY $(\leftrightarrow)$ connectivities.

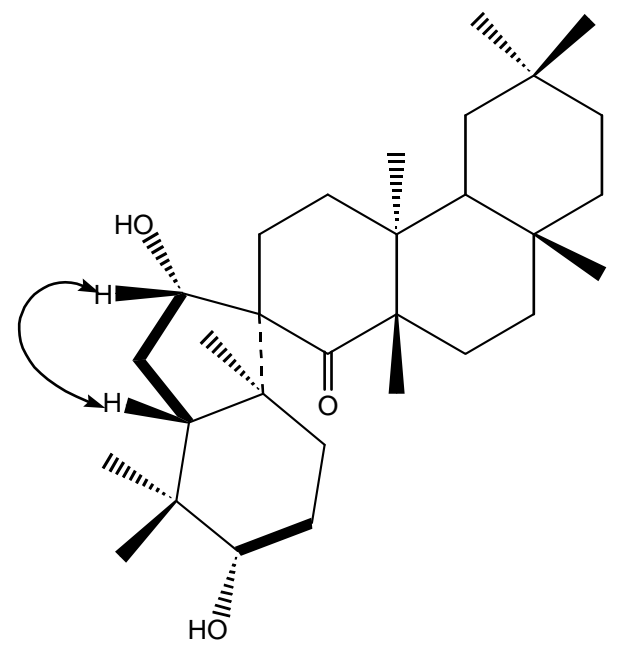

To the best of our knowledge spirowallichiione (1) has not been reported until now from any natural source, and thus it represents a new addition in the existing list of natural spirocompounds. The rearrangement observed in ring-B of spirowallichiione (1) and spirosupinanonediol, suggests the need to explore which enzyme is responsible for this process and whether this phenomenon is a characteristic feature of only Euphorbia species. 


\section{Conclusions}

Isolation of a rearranged pentacyclic triterpenoid of multiflorane class from E. wallichii containing a spiro center named spirowallichiione has been achieved and the structure elucidated with the aid of modern spectroscopic techniques including 2D-NMR.

\section{Experimental}

\section{General}

The melting point was recorded in glass capillary tubes using a Buchi 535 melting point apparatus and is uncorrected. Optical rotation was measured on a JASCO DIP-360 (Japan Spectroscopic Co. Ltd., Tokyo, Japan) digital polarimeter. The IR spectrum was recorded on a Shimadzu IR-460 instrument. The ${ }^{1} \mathrm{H}-\mathrm{NMR}$ and ${ }^{13} \mathrm{C}$-NMR spectra were recorded at 400 and $100 \mathrm{MHz}$, respectively, on a Bruker AM 400 spectrometer using TMS as an internal standard. The Electron Impact, Field Desorption and High Resolution Electron Impact mass spectra were scanned on a Jeol-JMS HX-110 mass spectrometer.

\section{Collection and Identification}

The plant material (all parts) was collected in August 2003, from Malumjabbah (a northern hilly area of Pakistan) and identified by Prof. Dr. Khalida Khatoon, Department of Botany, University of Karachi (Pakistan) where a voucher specimen is deposited (\# KK-08-03-19).

\section{Extraction and Isolation}

The collected plant material was dried under shade for a week. The dried material (5.5 kg) was then soaked in methanol (10 L) for eight days. The resulting extract was concentrated (308 g) by means of evaporation under vacuum and subjected to silica gel column chromatography using hexane, hexane-ethyl acetate, ethyl acetate and ethyl acetate-methanol as mobile phases. A white powder 1 (6.0 mg) was obtained with $10 \%$ ethyl acetate in hexane after washing with methanol.

Spirowallichiione (1): $\mathrm{C}_{30} \mathrm{H}_{50} \mathrm{O}_{3}$; white powder; mp 210-12 ${ }^{\circ} \mathrm{C}$; $[\alpha]_{\mathrm{D}}^{28}$ : -35 (c 1.03, $\mathrm{CHCl}_{3}$ ); $\mathrm{IRv}_{\max }$ $\left(\mathrm{CHCl}_{3}\right) \mathrm{cm}^{-1}: 3416(\mathrm{OH}), 1641(\mathrm{C}=\mathrm{O}) ;{ }^{1} \mathrm{H}-\mathrm{NMR}\left(\mathrm{CDCl}_{3}\right) \delta: 4.20(1 \mathrm{H}, \mathrm{dd}, J=7.1,7.1, \mathrm{~Hz}, \mathrm{H}-7), 3.47$ (1H, dd, $J=9.8,6.1 \mathrm{~Hz}, \mathrm{H}-3), 2.71$ (1H, dd, $J=14.3,6.0 \mathrm{~Hz}, \mathrm{H}-5), 2.03$ (1H, m, H-6a), 1.59 (2H, m, H-2), 1.53 (1H, m, H-6b), 1.22 (3H, s, H-26), 1.05 (3H, s, H-28), 0.99 (3H, s, H-30), 0.94 (3H, s, H23), 0.93 (3H, s, H-29), 0.88 (6H, s, H-25, H-27), 0.86 (3H, s, H-24); ${ }^{13} \mathrm{C}-\mathrm{NMR}\left(\mathrm{CDCl}_{3}\right) \delta: 34.3$ (C-1), 28.4 (C-2), 79.3 (C-3), 37.9 (C-4), 47.9 (C-5), 21.8 (C-6), 77.9 (C-7), 220.1 (C-8), 60.0 (C-9), 49.7 (C10), 30.0 (C-11), 31.4 (C-12), 38.7 (C-13), 54.4 (C-14), 25.5 (C-15), 35.9 (C-16), 30.6 (C-17), 43.7 (C18), 34.9 (C-19), 28.2 (C-20), 33.9 (C-21), 36.4 (C-22), 29.8 (C-23), 16.7 (C-24), 17.4 (C-25), 22.4 (C26), 21.8 (C-27), 31.5 (C-28), 34.4 (C-29), 32.9 (C-30); HMBC: see Figure 2; COSY-45: see Figure 3;

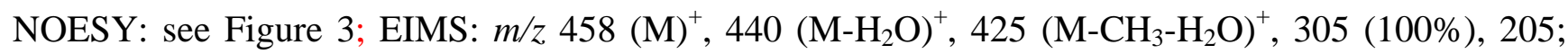
HREIMS: 458.3787 (calcd. for $\mathrm{C}_{30} \mathrm{H}_{50} \mathrm{O}_{3}, 458.3762$ ), 440.3668 (calcd. for $\mathrm{C}_{30} \mathrm{H}_{48} \mathrm{O}_{2}, 440.3656$ ), 
425.3317 (calcd. for $\mathrm{C}_{29} \mathrm{H}_{45} \mathrm{O}_{2}$, 425.3320 ), 305.2440 (cacld. for $\mathrm{C}_{20} \mathrm{H}_{33} \mathrm{O}_{2}, 305.2482$ ), 205.1942 (calcd. for $\mathrm{C}_{15} \mathrm{H}_{25}$, 205.1956); FDMS: $m / z 458$.

\section{References}

1. Smith-Kielland, I.; Dornish, J.M.; Malteruel, K.E.; Hvistendahl, G.; Romming, C.; Bockman, O.C.; Kolsaker, P.; Stenstrom, Y.; Norelal, A. Cytotoxic triterpenoids from the Leaves of Euphorbia pulcherrima. Planta Med. 1966, 62, 322-325.

2. Singla, A. K.; Pathak, K. Phytoconstituents of Euphorbia species. Fitoterapia 1990, LXI, 483516.

3. Saraf, S.; Dixit, V.K. Antihepatotoxic principles of Euphorbia antisyphilitica. Indian Drugs 1994, 31, 28-31.

4. Singla, A.K.; Pathak, K. Constituents of Banisteriopsis caapi. Fitoterapia 1991, LXII, 453-454.

5. Wu, L. Preparation of compound ointments for psoriasis. Faming Zhuanli Shenqing Gongkai Shuomingshu, 1993; [Chem. Abst. 1994, 120, 331115x].

6. Fakunle, C.O.; Connolly, J.D.; Rycroft, D.S. Enukokurin B and C, two other new jatrophane diterpenoide esters from the latex of Euphorbia laterifolia. Fitoterapia 1992, LX111, 329-332.

7. Satyanarayana, V.; Krupadanam, G.L.D.; Srimannarayana, G. Tetracyclic triterpenes from the latex of Euphorbia nivulia. Fitoterapia 1992, LXII, 82-83.

8. Lal, A.R.; Cambie, R.C.; Rutledge, P.S.; Woodgta, P.D. ent-Pimarane and ent-abietane diterpenes from Euphorbia fidjiana. Phytochemistry 1990, 29, 2239-2246.

9. Ahmad, V.U.; Hussain, H.; Hussain, J.; Jassbi, A.R.; Bukhari, I.A.; Yasin, A.; Choudhary, M.I.; Dar, A. New bioactive diterpenoid from Euphorbia decipiens. Z. Naturforsch. 2002, 57b, 10661071.

10. Jassbi, A.R.; Zamanizadehnajari, S.; Tahara, S. Chemical constituents of Euphorbia marschalliana Boiss. Z. Naturforsch. 2004, 59c, 15-18.

11. Ahmad, V.U.; Zahid, M.; Khan, T.; Asim, M.; Ahmad, A. Chemical constituents of Euphorbia heteradenia. Proc. Pak. Acad. Sci. 2002, 39, 201-206.

12. Vasas, A.; Hohmann, J.; Forgo, P.; Szabó, P. New tri- and tetracyclic diterpenes from Euphorbia villosa. Tetrahedron 2004, 60, 5025-5030.

13. Parvez, M.; Ahmad, V.U.; Hussain, J.; Farooq, U. 3,7,17-Tri-O-acetyl-5-O-butanoyl-13,15dihydroxymyrisinol. Acta Crystallogr. 2004, E60 148-150.

14. Corea, G.; Fattorusso, C.; Fattorusso, E.; Lanzotti, V. Amygdaloidins A-L, twelve new $13 \alpha-\mathrm{OH}$ jatrophane diterpenes from Euphorbia amygdaloides L. Tetrahedron 2005, 61, 4485-4494.

15. Ahmad, V.U.; Hussain, H.; Bukhari, I.A.; Hussain, J.; Jassbi, A.R.; Dar, A. Antinociceptive diterpene from Euphorbia decipiens. Fitoterapia 2005, 76, 230-232.

16. Ahmad, V.U.; Hussain, J.; Hussain, H.; Farooq, U.; Ullah, F.; Lodhi, M.A.; Choudhary, M.I. Two new diterpene polyesters from Euphorbia decipiens. Nat. Prod. Res. 2005, 19, 267-274.

17. Feizbakhsh, A.; Bighdeli, M.; Tehrani, M.S.; Rustaiyan, A.; Masoudi, S. Chemical constituents of essential oil of Euphorbia teheranica Boiss., a species endemic to Iran. J. Essen. Oil Res. 2004, 16, 40-41. 
18. Ravikanth, V.; Reddy, V.L.N.; Rao, T.P.; Diwan, P.V.; Ramakrishna, S.; Venkateswarlu, Y. Macrocyclic diterpenes from Euphorbia nivulia. Phytochemistry 2002, 59, 331-335.

19. Hohmann, J.; Rédei, D.; Forgo, P.; Molnár, J.; Dombi, G.; Zorig, T. Jatrophane diterpenoids from Euphorbia mangolica as modulators of the multidrug resistance of L5128 mouse lymphoma cells. J. Nat. Prod. 2003, 66, 976-979.

20. Wang, H.; Zhang, X.; Cai, X.; Ma, Y.; Luo, X. Three new diterpenoids from Euphorbia wallichii. Chin. J. Chem. 2004, 22, 199-202.

21. Pan, L.; Zhou, P.; Zhou, X.; Peng, S.; Ding, L.; Uiu, S. X. Skeleton-rearranged pentacyclic diterpenoids possessing a cyclobutane ring from Euphorbia wallichii. Org. Lett. 2006, 8, 27752778.

22. Matsunaga, S.; Morita, R.; Ishida, T.; Inoue, M.; Shigi, M.; Miyamae, A. The structure of spirosupinanonediol, a triterpenoid bearing a novel skeletal system from Euphorbia supine. J. Chem. Soc.Chem. Commun. 1984, 1128-1129.

Sample Availability: Samples of the compounds are available from the corresponding author.

(C) 2008 by MDPI (http://www.mdpi.org). Reproduction is permitted for noncommercial purposes. 